\title{
Atitudes Sociais de Professores em RelaÇão À Inclusão: Formação e MUdANÇA ${ }^{1}$ \\ Social Attitudes of Teachers in Relation to Inclusion: Training and CHANGE
}

\author{
Camila Mugnai VIEIRA² \\ Sadao OMOTE ${ }^{3}$
}

\begin{abstract}
RESUMO: Como todo ser humano, os professores constroem concepçóes, atitudes sociais, representações, crenças e expectativas em relação ao mundo e às pessoas ao seu redor. No contexto de sala de aula, esses elementos referem-se aos seus alunos e ao seu desempenho escolar. O trabalho docente pode ser influenciado por diversas variáveis. É propósito deste ensaio teórico examinar, especificamente, as atitudes sociais em relação à inclusão e às possíveis intervençóes para modificá-las. São discutidas eventuais conexôes entre as atitudes sociais em relação à inclusão e às variáveis sociodemográficas dos professores, como gênero, idade, área de formaçâo, área de atuação, contato prévio com estudantes público-alvo da Educação Especial, sentimento de autoeficácia, entre outras. Ademais, são abordados os efeitos de algumas variáveis ambientais e de alguns aspectos relacionados aos próprios alunos. Propóem-se que, para além do treinamento técnico, a capacitação docente aborde aspectos atitudinais e interacionais. O domínio de conhecimentos especializados e a competência no uso de diferentes recursos avançados são relevantes, mas a sua eficiência na construção da Educação Inclusiva depende do contexto sociopsicológico criado por professores genuinamente favoráveis à inclusão.
\end{abstract}

PALAVRAS-CHAVE: Educação Inclusiva. Formação de professores. Interação professor-aluno.

\begin{abstract}
Like every human being, teachers build conceptions, social attitudes, social representations, beliefs, and expectations in relation to the world and the people around them. In the classroom context, these elements refer to their students and the school performance of these students. Teaching can be influenced by several variables. The purpose of this theoretical essay is to examine teachers' social attitudes toward inclusion and possible interventions to modify them. The relationship between social attitudes toward inclusion and teachers' sociodemographic variables are discussed, such as gender, age, area of training, area of activity, prior contact with Special Education students, feeling of self-efficacy, among other features. In addition, the effects of some environmental variables and aspects related to the students themselves are discussed. It is proposed that in addition to technical training, teacher training should address attitudinal and interactional aspects. The domain of specialized knowledge and the competence in the use of different advanced resources are relevant, but their efficacy in the building of Inclusive Education depends on the socio-psychological context created by teachers who really support inclusion.
\end{abstract}

KEYWORDS: Inclusive Education. Teacher training. Teacher-student interaction.

\section{INTRODUÇÃo}

Uma particularidade marcante do ser humano é o seu desenvolvimento aprimorado e diversificado de aspectos cognitivos, afetivos e comportamentais, comparativamente aos assim chamados animais infra-humanos. Esses atributos permitem uma ampla gama de variaçóes no convívio com seus pares coespecíficos, permitindo a cada pessoa uma possibilidade quase ilimitada de lidar com diferentes situaçóes. Tal possibilidade é de particular importância em atividades que dependem direta ou indiretamente da participaçáo de outras pessoas, o que ocorre

\footnotetext{
${ }^{1}$ https://doi.org/10.1590/1980-54702021v27e0254

${ }^{2}$ Doutora e Pós-doutoranda em Educação pela Universidade Estadual Paulista (UNESP). Marília / São Paulo / Brasil. Docente da Disciplina de Psicologia e do Mestrado Profissional Ensino em Saúde da Faculdade de Medicina de Marília (FAMEMA). E-mail: camilamugnai@gmail.com. ORCID: http://orcid.org/0000-0001-7564-6218

${ }^{3}$ Livre-Docente. Professor Titular aposentado do Departamento de Educação Especial da Faculdade de Filosofia e Ciências. Universidade Estadual Paulista (UNESP). Marília / São Paulo / Brasil. E-mail: somote@uol.com.br. ORCID: https://orcid.org/0000-0003-2455-4529
} 
em praticamente todas as situaçôes, considerando que o ser humano é gregário. Mais ainda, com a globalização crescente, são patentes a diversidade de padróes de interação e as respectivas demandas de ajustamento.

Os comportamentos humanos instrumentais, aqueles direcionados a algum alvo com o propósito de produzir algum efeito, são fortemente influenciados pelos sentimentos e pelas crenças associados a esse alvo. Desse modo, a relação entre o afeto e a cognição tende a determinar a natureza do comportamento direcionado a esse alvo. Uma parte expressiva das açóes praticadas pelas pessoas, no cotidiano, tem essa dinâmica, da qual, em geral, a pessoa não tem consciência, o que pode levá-la a não ter percepção crítica de seus próprios comportamentos.

Uma situação social de especial importância diz respeito a interações entre pessoas, que, propositadamente ou não, resultam na aquisição de novas cogniçóes a respeito de diferentes objetos, acompanhadas muitas vezes de algum sentimento, o que pode influenciar a eventual ação da pessoa em relação a esse objeto. Isso ocorre em muitas situaçóes, formalmente constituídas ou não, como nas relaçóes intrafamiliares, de trabalho, de lazer, etc. O contexto de interesse para os propósitos deste texto é o da instituição escolar, em especial a relação interpessoal e social que ocorre na sala de aula.

Neste texto, pretende-se levantar a necessidade de uma dimensão frequentemente pouco valorizada e pouco considerada na formação de professores para a efetividade de uma educação escolar inclusiva e de qualidade para crianças e jovens e convidar o leitor a refletir sobre ela. Trata-se de variáveis pessoais do professor, mais especificamente as suas atitudes sociais em relação à inclusão e às possibilidades de modificá-las. Outras variáveis pessoais do professor, relevantes para o seu exercício docente, como habilidades sociais, autoeficácia, crença em um mundo justo, concepçóes sobre o ensino e a aprendizagem etc., são também investigadas. No entanto, a opção por atitudes sociais se fundamenta na proposição de que estas estão subjacentes às açóes significativas das pessoas (Rodrigues et al., 2007).

A relação ensino-aprendizagem é primariamente uma relação interpessoal dialética entre quem ensina e quem aprende. Considerando que muito da aprendizagem na sala de aula ocorre de modo coletivo, a aprendizagem escolar de cada um dos alunos depende da qualidade da relaçáo entre o professor e cada aluno, bem como entre as pessoas que compóem a classe, sendo o professor o grande regente das relaçóes interpessoais e sociais que ocorrem no espaço social da sala de aula. Considerar as relaçóes sociais no contexto escolar torna-se imprescindível para a compreensão do fenômeno educacional. É necessária a sensibilização para as questôes relacionadas à subjetividade dos professores, que vivenciam cotidianamente em sua prática diversos desafios, diversas angústias e conquistas (Omote \& Vieira, 2018).

Prover ensino de qualidade para a formação de novas geraçóes capazes de enfrentar com competência os desafios postos pela moderna sociedade em constante e rápida transformação é um discurso frequente proferido pelas autoridades e pelos gestores públicos. A política e a prática, nessa direção, têm se caracterizado pela preocupação em aumentar a verba destinada à Educação, equipar as instituiçóes escolares com modernos laboratórios e recursos de altas tecnologias e capacitar os professores. Naturalmente, tudo isso é relevante, mas não suficiente para a melhoria da qualidade da educação escolar. 
Os professores representam a peça principal no processo de educação escolar. Como todo ser humano, os professores constroem conhecimento a respeito do mundo e das pessoas ao redor. Tais conhecimentos se constituem de concepçóes, atitudes sociais, crenças e expectativas. No contexto da sala de aula, o foco recai sobre os alunos e o seu desempenho escolar. As atitudes docentes podem decorrer de sua experiência prática e podem ser influenciadas por percepçóes equivocadas, preconceitos, valores ou experiências anteriores positivas ou negativas. Esses elementos influenciam as suas interações e condutas em relação aos seus alunos, incluindo os que fazem parte do público-alvo da Educação Especial (PAEE) ${ }^{4}$, de modo favorável ou desfavorável (Omote \& Vieira, 2018). Portanto, a capacitação de professores, da formação inicial à formação continuada, precisa levar em consideração suas variáveis pessoais. Não é suficiente o conhecimento sobre os variados fundamentos da Educação Especial e da Educação Inclusiva nem o domínio de procedimentos e recursos avançados ${ }^{5}$. As atitudes sociais em relação à inclusão favorável representam uma possibilidade de que os conhecimentos e os recursos disponíveis são mobilizados para a construção da Educação Inclusiva.

Dentre tantas variáveis pessoais dos professores que podem afetar diretamente o seu trabalho docente, é propósito deste ensaio teórico examinar, particularmente, as atitudes sociais em relação à inclusão e às possíveis estratégias para modificá-las, as quais devem fazer parte do processo de formação docente. Para tanto, são tratados aspectos conceituais relacionados às atitudes sociais e às estratégias para suas mudanças. São também discutidas possíveis conexões entre as atitudes sociais em relação à inclusão e algumas variáveis sociodemográficas dos professores, como gênero, idade, tempo de formação, área de atuação, contato prévio com alunos com deficiências, sentimento de autoeficácia, entre outras. Ademais, são apresentados efeitos das variáveis ambientais, como sobrecarga de trabalho e apoios especializados, além de aspectos relacionados aos próprios alunos, tipos de deficiências e graus de comprometimento. Propóem-se, a partir dos resultados dos estudos analisados, reflexóes a respeito da capacitação docente para além do treinamento técnico, aproveitando as estratégias relatadas na literatura e nas experiências exitosas para configurar propostas de formação de professores que abarquem conhecimento e técnica, mas também, ou especialmente, os aspectos atitudinais e relacionais ${ }^{6}$.

\section{ATITUdes SOCIAIS DE PROFESSORES EM RELAÇÁO À INCLUSÁO}

As atitudes sociais são descritas como predisposiçóes psíquicas ou afetivas com relação a uma pessoa, a um grupo, a alguns objetos ou fenômenos, como situaçóes e ideias, referi-

\footnotetext{
${ }^{4}$ A legislação brasileira emprega a expressão "público-alvo da Educação Especial” (PAEE) para se referir a pessoas com deficiências, altas habilidades/superdotação e transtornos globais do desenvolvimento. Embora algumas pesquisas apresentadas tenham utilizado nos textos originais as expressóes "pessoas com deficiências" ou "alunos com necessidades especiais", optou-se, neste ensaio, pela adoção do termo PAEE para atualização e uniformização da terminologia no texto. Ademais, o foco da discussão recai sobre as atitudes sociais em relação ao objeto social “inclusão", sem a especificação de quais são os grupos sociais em questão. Quando necessário, foi dado devido destaque à condiçáo dos alunos, explicitada no texto por terminologia específica.

${ }^{5}$ Há tantos outros fenômenos envolvidos nos processos de ensino e de aprendizagem no contexto escolar. Muitas transformaçốes são necessárias, em termos de políticas públicas, currículos, estruturas, materiais, recursos e cultura escolar. Aspectos econômicos e sociais mais amplos na sociedade brasileira, como a pobreza e suas repercussốes, a violência, o preconceito em relação a determinados grupos sociais, ainda precisam ser superados. Não se ignoram esses fenômenos, estreitamente relacionados à qualidade da educação escolar, mas nấo seráo aqui discutidos por fugirem ao escopo do texto.

${ }^{6}$ No desenvolvimento dessas análises, são utilizados estudos realizados nas duas últimas décadas. Mesmo as pesquisas realizadas em contextos distintos do sistema educacional brasileiro são consideradas, na extensão em que os seus achados contribuem para a compreensão do fenômeno em estudo.
} 
dos como objetos atitudinais. As atitudes sociais relacionam-se necessariamente a algum objeto atitudinal, podendo ser positivas ou negativas, ou seja, favoráveis ou desfavoráveis. As atitudes sociais se compóem de três elementos: o cognitivo, o afetivo e o comportamental. O eixo cognitivo diz respeito ao conhecimento sobre o objeto atitudinal, isto é, o conceito, a representação cognitiva que o sujeito possui acerca desse objeto, incluindo avaliaçóes, julgamentos e crenças a respeito de algo ou alguém. Já o eixo afetivo indica os sentimentos favoráveis ou desfavoráveis ao objeto atitudinal, agregando afetos positivos ou negativos. E o eixo comportamental refere-se às açóes do sujeito direcionadas ao objeto atitudinal, coerentemente com as crenças e os sentimentos em relação a ele (Rodrigues et al., 2007).

Com o avanço nos debates sobre a inclusão, sobretudo a partir da Declaração de Salamanca (Organização das Naçóes Unidas para a Educação, a Ciência e a Cultura [UNESCO], 1994), cresceu o interesse nas pesquisas sobre atitudes sociais dos professores em relação à inclusão. A análise cuidadosa dos resultados dessas pesquisas pode sinalizar quais são as ações dos professores no cotidiano escolar (Omote et al., 2005), visto que uma ampla gama de variáveis pode estar relacionada a essas atitudes sociais. As investigaçóes a esse respeito apresentam resultados diversificados não inteiramente conclusivos. A despeito dessas imprecisóes, a importância de algumas variáveis é evidenciada em muitas pesquisas, destacando-se o gênero, a idade cronológica, o tempo de experiência docente, a experiência no ensino de alunos com deficiência e a formação profissional.

Os estudos realizados com professores trazem resultados aparentemente desencontrados quanto à relação entre o gênero e as atitudes sociais em relação à inclusão. As atitudes sociais de participantes do gênero feminino em relação à inclusão podem ser mais favoráveis que as do gênero masculino (Brunhara et al., 2019; Saloviita, 2020) ou, contrariamente, os do gênero masculino podem apresentar atitudes sociais mais favoráveis que os do gênero feminino (Capellini et al., 2013; Chopra, 2008; Gouveia, 2019). Uma terceira possibilidade também foi evidenciada, indicando não haver relação entre o gênero dos participantes e essas atitudes sociais (Parasuram, 2006).

Outra característica dos professores que pode manter alguma conexão com suas atitudes sociais em relação à inclusão é a idade cronológica deles. Aqui também os resultados são bastante desencontrados. Os estudos revelam que os mais jovens podem apresentar atitudes mais favoráveis que os menos jovens (Balboni \& Pedrabissi, 2000; Saloviita, 2020), mas há também resultado oposto, ou melhor, que evidenciam atitudes sociais mais favoráveis entre os menos jovens que entre os mais jovens (Capellini et al., 2013; Gouveia, 2019). Há ainda estudos que mostram não haver diferença entre participantes jovens e velhos (Pereira Júnior, 2009; Souza, 2011).

O tempo de experiência docente e as atitudes sociais em relação à inclusão podem apresentar uma relação inversa, dado que professores mais experientes têm atitudes sociais mais desfavoráveis à inclusão, como evidenciado por Gal et al. (2010). Várias pesquisas apontaram nessa direção, mas há resultados diversificados. Contrariamente, os resultados encontrados por Leung e Mak (2010) mostram que os professores participantes com mais de 10 anos de experiência docente tiveram atitudes mais positivas do que aqueles com menos de 10 anos, indicando engajamento pessoal, envolvimento e satisfação com o trabalho como fatores responsáveis por 
essa diferença. Já Chopra (2008) não encontrou diferenças entre professores com mais de 10 anos de docência e aqueles com menos de 10 anos.

Um dos componentes das atitudes sociais é o cognitivo, constituído por crenças a respeito do objeto atitudinal. Essas crenças são frequentemente construídas por meio de informações adquiridas em fontes não necessariamente confiáveis, que podem transmitir preconceitos e estereótipos. Nesse sentido, pode-se supor que o contato direto com o objeto atitudinal pode contribuir para construir novas crenças a respeito dele, tanto positivas quanto negativas. O contato com pessoas PAEE pode favorecer a construção de atitudes sociais positivas em relação à inclusão, se o convívio levar à melhor compreensão das necessidades ou limitaçóes. Além disso, as habilidades e as potencialidades até então não reveladas podem ganhar visibilidade. $\mathrm{O}$ aprendizado advindo da experiência com alunos PAEE pode trazer segurança ao professor além de proximidade, o que pode mobilizar afeto mútuo e, por conseguinte, maior aceitação desses alunos ${ }^{7}$.

Confirmando a hipótese de contato, os achados de Avramidis e Kalyva (2007) e de Saloviita (2020) apontam que as experiências de professores com alunos PAEE são fundamentais para o desenvolvimento de atitudes favoráveis à inclusão. Um outro estudo evidenciou que essa diferença significante só foi observada entre os professores de $5^{\mathrm{a}}$ a $8^{\mathrm{a}}$ série (atualmente $6^{\circ}$ ao $9^{\circ}$ ano) do Ensino Fundamental (Delgado-Pinheiro, 2003). Em apoio a esse resultado, nos estudos de Brito (2017) e Silva (2008), com os professores do $1^{\circ}$ ao $5^{\circ}$ ano do Ensino Fundamental, não foi encontrada diferença significante nas atitudes sociais entre os que tinham experiência com alunos PAEE e os que não tinham.

O contato por si só pode não garantir atitudes sociais mais positivas. As atitudes sociais dos professores podem tornar-se mais favoráveis à inclusão se as experiências com os alunos PAEE em sala de aula forem positivas (Avramidis \& Kalyva, 2007; Kuyini et al., 2018; Saloviita, 2020). É necessário que esse contato ocorra em situaçóes adequadas e seja concomitante a outras condições como a informação, o apoio e a ampliação de recursos que ensejem experiências favoráveis com estudantes com deficiência.

A área de formação e/ou atuação profissional pode relacionar-se às atitudes sociais no tocante à inclusão pela própria especificidade da escolha ou vocação, que pode ser influenciada pelas atitudes prévias dos sujeitos. Uma pessoa que opta por seguir uma carreira na área da Saúde provavelmente tem um perfil diferenciado daquela que escolhe a área de Ciências Exatas, em termos de características psicológicas, vivências e demais condiçóes que podem influenciar a sua formação global. Adicionalmente, espera-se que os conhecimentos e as experiências adquiridos em cursos e profissóes específicas possam modificar as atitudes.

Algumas pesquisas, como as de Kijima (2008), Silva (2008) e Souza (2017) indicam que eventuais diferenças encontradas entre sujeitos de formaçôes distintas podem ser anteriores à escolha dos cursos. A opção por determinada área de formação em nível de especialização parece ser influenciada pelas atitudes sociais em relação à inclusão e não pelo conteúdo curricular

\footnotetext{
${ }_{7}^{7}$ A "hipótese de contato", de Allport (1954), parte do pressuposto de que o contato entre membros de grupos distintos permite verificar as semelhanças existentes quanto aos valores, às ideias e às emoçóes, levando a reelaborar a percepção inicial de diferenças (Crochik, 2001). Allport (1954) salientou que as condiçōes para esse contato ser bem-sucedido incluem a frequência, a diversidade, a duração, o status de membros dos grupos em interação, se há competição ou cooperação e se o contato é ou não voluntário.
} 
do curso. Assim, Kijima (2008) verificou que, já antes de iniciarem o curso de especialização, os professores que haviam feito a opção pela formação em Educação Especial apresentavam atitudes sociais mais favoráveis dos que haviam feito opção por outras áreas de Educação. Semelhantemente, Souza (2017) constatou que, dentre os professores que estavam fazendo curso de especialização em Educação Especial, aqueles que haviam feito opção pela área de Deficiência Intelectual apresentavam atitudes sociais mais favoráveis do que quem havia feito opçáo pela área de Deficiência Auditiva. Talvez não apenas a escolha da área, na qual os professores buscam a sua formação especializada, seja influenciada por suas atitudes sociais em relação à inclusão, mas também por procurarem uma capacitação em nível de especialização (Silva, 2008). O estudo de Silva (2008) evidenciou que os professores com especialização apresentaram atitudes sociais mais favoráveis do que os seus colegas sem especialização. Em vista do delineamento da pesquisa de Silva, não é possível levantar a hipótese acerca da possibilidade de o curso de especialização ter contribuído para a mudança de atitudes sociais ${ }^{8}$.

Outras variáveis pessoais e demográficas do professor podem estar relacionadas às suas atitudes sociais em relação à inclusão, como, por exemplo, as habilidades sociais, a autoeficácia e até a regiấo do Brasil na qual atua. As condiçóes concretas do ambiente de trabalho, a carga horária docente, o acesso a recursos e o apoio recebido também são importantes. Uma característica do professor que vem sendo progressivamente valorizada se refere às suas habilidades sociais. Foi encontrada correlação positiva significante entre as atitudes sociais em relação à inclusão e ao fator 4 do Inventário de Habilidades Sociais (Del Prette \& Del Prette, 2001), que corresponde à capacidade de "autoexposição a desconhecidos e situaçóes novas" (Silva, 2008). Esse resultado sugere como as atitudes sociais em relação à inclusão podem estar relacionadas à disposição psicológica de enfrentar desafios. Parece plausível essa possibilidade, na medida em que ser favorável à inclusão pode significar o enfrentamento de situaçôes novas, eventualmente até temidas. Isso pode estar relacionado a uma outra variável pessoal do professor, nem sempre considerada devidamente, o senso de autoeficácia. O modo como o professor se percebe capaz de atuar com alunos com deficiências pode afetar suas atitudes sociais em relação à inclusão (Berry, 2010). Alguns estudos, como os de Kuittinen (2017) e Yada \& Savolainen (2017), indicam haver correlação positiva significante entre autoeficácia e atitudes sociais, especialmente entre professores em serviço.

As pesquisas realizadas na Finlândia indicam que docentes das séries iniciais, correspondentes ao Ensino Fundamental no Brasil, são mais favoráveis à inclusão do que professores dos níveis correspondentes ao Ensino Médio e ao Ensino Superior brasileiros (Saloviita, 2020). Ademais, a pesquisa de Gouveia (2019) indica que, entre professores portugueses, de uma maneira geral, os de escola pública apresentam atitudes mais inclusivas do que os da escola privada.

Capellini et al. (2013) compararam as atitudes sociais de professores das diferentes regióes do Brasil e verificaram que os profissionais das regióes Centro-Oeste, Norte e Nordeste juntos apresentam escores significantemente mais altos, comparativamente aos das regióes Sul e Sudeste. Resta verificar em que variáveis sociodemográficas os professores dessas regióes se diferenciam.

As variáveis circunstanciais do contexto escolar podem estar associadas às atitudes sociais em relação à inclusão. Os professores confiantes em suas redes de apoio, com acesso

${ }^{8}$ Esta questão será discutida no próximo item. 
suficiente a recursos educacionais, como um assistente de ensino em sala de aula, e com baixa expectativa em relação ao aumento da carga de trabalho com alunos PAEE, têm atitudes mais positivas (Saloviita, 2020). Uma década antes, Gal et al. (2010) já haviam evidenciado que os professores com mais horas de trabalho por dia tinham atitudes sociais mais negativas do que aqueles com menos carga horária diária.

Algumas características do aluno PAEE e seu grau de comprometimento podem influenciar as atitudes dos docentes. As condiçóes mais facilmente aceitas pelos professores são distúrbios relacionados a problemas leves de aprendizado. As condiçóes mais difíceis para serem aceitas e que geram atitudes menos favoráveis são autismo, surdez, deficiências intelectuais graves, deficiências múltiplas e sérios problemas emocionais e comportamentais (Saloviita, 2020). A inclusão de alunos com deficiências físicas ou sensoriais é melhor aceita do que daqueles com problemas cognitivos, emocionais ou comportamentais, sendo estes últimos alvos de atitudes sociais mais negativas (Gal et al., 2010).

Os resultados inconclusivos recomendam novas investigaçóes com um delineamento que permita compreender melhor a relação entre tais atitudes sociais e algumas das variáveis que podem ser determinantes a serem consideradas no planejamento de capacitação de professores para o ensino inclusivo de estudantes PAEE. Seguramente, as atitudes sociais em relação à inclusão não são construídas ou influenciadas por variáveis específicas de modo isolado. Elementos constituintes dos sujeitos e dos objetos atitudinais, bem como aspectos do contexto e das interaçôes sociais parecem relacionar-se de modo complexo no processo de formação das atitudes sociais em relação à inclusão. É preciso buscar a relação entre as atitudes sociais e cada uma das variáveis específicas envolvidas, como também o efeito das interaçôes entre estas sobre as atitudes sociais.

\section{FORMAÇÁO DE PROFESSORES E MUDANÇA DE SUAS ATITUDES SOCIAIS EM RELAÇÁO À INCLUSÃO}

O professor precisa tornar-se consciente dos fatores que interferem em seu julgamento dos alunos e que afetam as estratégias pedagógicas adotadas, a avaliação realizada e o modelo que oferece em relação às interaçóes sociais em sala de aula. É necessário que os processos de formação o levem ao autoconhecimento e à busca por mudanças, no sentido de desenvolvimento de condutas eficazes para os processos de ensino e de aprendizagem, tendo em vista a ampla diversidade de necessidades do alunado (Omote \& Vieira, 2018).

Além da aquisição de conhecimentos e habilidades para o uso de recursos didático-pedagógicos especiais, o professor precisa adquirir competências para lidar com diferentes situaçóes sociais que podem surgir no ambiente de sala de aula e da escola, envolvendo a questão da Educação Inclusiva e suas implicaçóes. Isso envolve uma série de características do professor, aqui referidas como variáveis pessoais. No presente texto, são tratadas especificamente as suas atitudes sociais em relação à inclusão por ser a variável pessoal mais estreitamente relacionada à resposta do professor diante de desafios colocados pela implementação da Educação Inclusiva.

De modo geral, os cursos de capacitação não têm contemplado as atitudes sociais do professor em relação à inclusão. Não se trata da introdução dessa temática no conteúdo programático para ser debatida para a compreensão da sua relevância. Mais do que isso, por meio de diferentes atividades programadas, a capacitação deve permitir aos professores modificarem 
suas atitudes sociais tornando-as genuinamente favoráveis à inclusão. Assim, as competências e os conhecimentos adquiridos poderão ser utilizados efetivamente em prol da promoção da inclusão escolar.

Para a mudança de atitudes sociais, os seus três componentes (cognitivo, afetivo e comportamental) precisam ser convenientemente trabalhados. A exposição a novas informações é uma estratégia potente para mudança de atitudes sociais. Nesse sentido, há várias possibilidades de manejo de conteúdos e situaçóes que podem gerar novos conhecimentos e mudança conjunta de componentes cognitivos, afetivos e comportamentais. Para tanto, precisam ser oferecidas informaçóes favoráveis a respeito do objeto atitudinal e oportunidades de realizar atividades que favoreçam o desenvolvimento de afetos positivos. Convenientemente, combinadas essas experiências, podem ser criadas tendências e açôes pró-objeto atitudinal. Tais procedimentos podem ser incluídos em programas de capacitação para professores ainda em formação, cursos pontuais e disciplinas específicas (Golmic \& Hansen, 2012; Omote et al., 2005; Sharma, 2012).

A formação do professor não se encerra em uma formação inicial e básica, nem mesmo em capacitaçôes continuadas, pois é um processo dinâmico e permanente. Assim sendo, deve ocorrer a reflexão contínua sobre sua prática profissional. São necessários espaços de acolhimento, escuta e compartilhamento de vivências entre os pares, que propiciem aos professores a experiência de contato com suas próprias fragilidades, dúvidas e barreiras psicológicas em busca da construção de maior valorização e sentido no ofício docente. Tal proposta deve estar pautada em uma cultura escolar que priorize os valores humanos capazes de favorecer um trabalho cooperativo, relaçóes interpessoais saudáveis e empáticas, maior autoestima e motivação de todos (Sekkel et al., 2010). Pode ser um importante desafio a ser enfrentado pela liderança da gestâo escolar.

As lutas diárias dos professores no cotidiano escolar não são poucas. A necessidade de mediação do processo de construção de conhecimento e a complexidade que isso implica geram várias demandas, além dos novos papéis e das novas responsabilidades a serem assumidos diante da proposta da Educação Inclusiva. Nesse contexto, independentemente de seu posicionamento político ou da abordagem de ensino que assumem, os professores constroem crenças, expectativas e atitudes sociais que influenciam suas ações e interaçóes com seus alunos. Assim, há variáveis individuais dos professores que precisam ser consideradas para que se construa a educação de qualidade que se pretende. Conhecer essas características pessoais e aprender a utilizá-las em benefício do trabalho docente devem ser aspectos trabalhados na formação docente (Omote \& Vieira, 2018).

É necessário aguçar a capacidade do professor de refletir sobre a sua própria prática, autoavaliar-se e reconstruir suas condutas com autonomia, em conformidade com a realidade que se apresenta na sala de aula. A auto-observação, a reflexão e a busca de transformação pessoal devem ser contínuas. Devem ampliar-se espaços de encontro entre os professores e destes com outros setores da escola, que, em interação, caminhem para a construção de uma cultura escolar inclusiva (Santos et al., 2008).

Os estudos sobre atitudes sociais indicam que os professores sentem que lhes falta o preparo adequado para atuarem no ensino inclusivo e apontam a necessidade de investimento na sua formação inicial, assim como em capacitaçóes em serviço (Verde et al., 2020). Cursos de 
curta duração sobre as necessidades de alunos com deficiência ou a introdução desses tópicos em algumas disciplinas de cursos de formação têm sido empregados com o propósito de capacitar os futuros professores para o ensino inclusivo. Estudos sobre a formação de pedagogos indicam um ganho de espaço da Educação Especial na Graduação, com a oferta de disciplinas com tópicos interessantes. No entanto, há limitaçóes e necessidade de mudanças para currículos que considerem a interdisciplinaridade, as especificidades relevantes de cada deficiência e da formação e habilitação dos pedagogos (Silva, 2009), assim como a capacitação e a experiência dos docentes que ministram as disciplinas e o tempo adequado dedicado à temática da inclusão (Cook, 2002).

O grande desafio na formação de professores é construir conhecimentos e atitudes que permitam lidar com situaçóes complexas e com os processos de ensino e de aprendizagem para a diversidade (Pletsch, 2009). A capacitação dos professores, além da compreensão das características e necessidades do aluno PAEE e da utilização de recursos para atendê-las, deve incluir também uma nova visão de ensino e de aprendizagem, fundada em atitudes favoráveis à inclusão (Omote et al., 2005). Se as atitudes negativas dos futuros professores não forem abordadas durante a formação inicial, elas podem dificultar o progresso da Educação Inclusiva nas escolas (Forlin et al., 2009).

Há algumas experiências de modificação de atitudes sociais dos professores em relação à inclusão, que, no conjunto, estão delineando um possível procedimento a ser incluído em cursos de capacitação. Essa possibilidade é particularmente promissora, considerando não haver mais dúvida de que a capacitação de professores para a Educação Inclusiva não mais pode limitar-se à aquisição de novos conhecimentos e de novas habilidades para o uso de recursos especiais, que se destinam ao ensino de estudantes com necessidades educacionais específicas.

Considerando que as atitudes sociais se constituem em um fenômeno complexo e multideterminado, o uso de diferentes estratégias deve ocorrer de modo articulado. Adicionalmente ao acesso a informaçóes, o contato com pessoas PAEE ou a oportunidade de vivências práticas no cotidiano escolar podem ser eficazes. Naturalmente, essas experiências precisam ser gerenciadas de maneira a prover vivência positiva capaz de criar disposição favorável ao objeto atitudinal.

Golmic e Hansen (2012) avaliaram os efeitos de uma "experiência inclusiva" sobre as atitudes sociais, os sentimentos e as preocupações de professores em formação. A intervenção consistiu em 12 semanas de atividades docentes em salas nas quais havia alunos com necessidades especiais, seguindo passos que propunham reflexão sobre suas atitudes, suas concepções, seus conhecimentos e suas habilidades durante o período em que lecionaram. Segundo os autores, após essa experiência, as atitudes sociais em relação à inclusão tornaram-se mais positivas.

Os Programas de Pós-Graduação ou cursos específicos sobre a Educação Especial e Educação Inclusiva podem trazer efeitos positivos, como apontou o estudo de Male (2011). Segundo esse autor, as atitudes sociais dos professores tornaram-se significantemente mais favoráveis à inclusão após 10 semanas do chamado "módulo introdutório" em um Programa de Pós-Graduação em Educação Especial e Educação Inclusiva. Em outro estudo, os professores que passaram por treinamentos apresentaram atitudes mais positivas em relação à filosofia geral da inclusão comparativamente àqueles que não passaram por essa capacitação (Avramidis \& Kalyva, 2007). 
Outras estratégias, além dos cursos e das capacitações pontuais, são a disponibilização de informação escrita sobre temas relacionados à Educação Especial e o contato dos professores com os profissionais da área. Kim et al. (2005) ofereceram um boletim informativo para professores do ensino comum escrito por profissionais da Educação Especial, o qual foi organizado em quatro partes, contendo informaçóes sobre alunos com deficiência, notícias sobre o tema, informações sobre Educação Especial e inclusão e feedback de professores do ensino inclusivo. Além disso, os professores do ensino comum tiveram contato semanal com o educador especial. Após a intervenção, esses professores apresentaram atitudes sociais mais positivas do que seus colegas que não passaram por essa experiência.

Um breve conjunto de atividades, organizadas na forma de um workshop, com a finalidade de prover informaçóes convincentes e vivências pró-inclusão, foi suficiente para modificar favoravelmente as atitudes sociais de professores participantes de um programa de capacitação (Menino-Mencia, 2020). As estratégias que levaram em consideração as variáveis pessoais e emocionais dos professores, na reflexão em relação à Educação Inclusiva, foram mais eficientes que o próprio curso para a mudança ocorrida. $\mathrm{O}$ uso de um procedimento como esse, em cursos de capacitação de professores para a Educação Inclusiva, pode ser bastante viável pela sua eficácia e pela sua brevidade. Foram apenas quatro horas de atividades, distribuídas em duas sessóes.

Mesmo em cursos de formação a distância, novas informaçóes favoráveis à inclusão expostas a professores podem gerar mudanças em suas atitudes sociais. Capellini et al. (2013) avaliaram as atitudes sociais de 2.648 profissionais da Educação antes e depois de um curso de aprimoramento em Educação Especial e Inclusiva, oferecido pelo Ministério da Educação, na modalidade de ensino a distância, e verificaram que as atitudes sociais em relação à inclusão tornaram-se mais favoráveis após o curso. As mudanças foram mais expressivas nos grupos com escores iniciais mais baixos, sugerindo que um curso dessa natureza pode ser particularmente efetivo para os professores com atitudes sociais iniciais menos favoráveis.

A despeito de muitas pesquisas apresentarem efeitos positivos de intervenções que propuseram promover mudanças de atitudes sociais em relação à inclusão, há resultados divergentes na literatura. Algumas intervenções não apresentaram efeitos positivos nas atitudes sociais em relação à inclusão (Wilkins \& Nietfeld, 2004; Woodcock et al., 2012). Possivelmente, aulas teóricas e leituras não são suficientes para modificar atitudes negativas de professores, uma vez que, além de aspectos cognitivos, envolvem componentes afetivos e comportamentais, que não são afetados necessariamente pelo acesso à informação. Gatti (2003) ressaltou que, para programas formativos terem impacto efetivo no modo de agir das pessoas, é imprescindível que considerem as condiçóes psicossociais e culturais dos sujeitos envolvidos, além de suas condições cognitivas, buscando integrar vida e trabalho dos participantes.

Outro elemento que possivelmente potencializa ações de capacitação docente é o trabalho em pequenos grupos. Cursos em larga escala, com um grande número de participantes, no formato de palestras e seminários, têm um efeito limitado. Mintz (2007) apontou que crenças, atitudes e valores não são facilmente tratados em grandes grupos e requerem aproximação entre as pessoas e discussóes aprofundadas. Martins (2006) indicou a importância da 
utilização de estratégias mais dinâmicas e significativas aos professores e a ampliação de espaços permanentes de estudos e de troca de experiências, dúvidas e angústias.

Um procedimento particularmente eficiente consiste em envolver os professores em atividades que pressupõem que suas atitudes sociais em relação à inclusão sejam favoráveis. Quando os professores se empenham no desenvolvimento de tais atividades, cria-se um estado psicológico conhecido por dissonância cognitiva (Festinger, 1957), se suas atitudes sociais não forem suficientemente favoráveis à inclusão. Na tentativa de solução desse conflito, as atitudes sociais podem tornar-se favoráveis para serem coerentes com a ação praticada. Merecem destaque aqui dois estudos: o de Gash (1993) e o de Vieira (2014).

Gash (1993) desenvolveu um programa para promoção de atitudes sociais positivas em relação às crianças PAEE. Os professores foram capacitados a ministrar aos seus alunos liçóes nas quais eram abordados os tipos de deficiência, as dificuldades que as pessoas com deficiência enfrentavam e os sentimentos que despertavam nelas. As atividades destinavam-se a oferecer oportunidade para que as crianças reconsiderassem suas ideias e percebessem essas pessoas de modo mais positivo. Os resultados apontam que os professores submetidos a esse procedimento apresentaram atitudes sociais mais positivas em relação aos alunos PAEE do que seus pares não submetidos ao procedimento.

Uma intervenção diferente foi desenvolvida por Vieira (2014), que capacitou professores para aplicarem a seus alunos um programa informativo sobre a temática das deficiências e da inclusão voltado ao público infantil, que utilizava estratégias pedagógicas e lúdicas variadas. A administração desse programa informativo pelos professores junto às respectivas classes resultou na mudança satisfatória de atitudes sociais dos alunos, tornando-os mais favoráveis à inclusão. Ao mesmo tempo, as atitudes sociais dos próprios professores sofreram mudanças, tornando-se mais favoráveis. Os professores, cujas atitudes sociais se modificaram após a administração do programa informativo, eram predominantemente aqueles que lecionavam em classes cujos alunos também apresentaram mudanças expressivas nas atitudes sociais após o programa informativo.

A implementação bem-sucedida da Educação Inclusiva requer muito mais que o treinamento de professores para o uso competente de recursos avançados de ensino, inclusive para estudantes PAEE. Na construção da Educação Inclusiva, os professores podem encontrar novas maneiras de trabalhar que requerem ação colaborativa com a equipe escolar e podem permitir a aquisição de novas habilidades sociais. Os professores podem ser conduzidos, nessa tarefa, à revisão das velhas práticas, em busca de outras alternativas para atender à demanda da Educação Inclusiva (Saloviita, 2020). Quando ocorre a cooperação entre os professores, com apoio mútuo, a implementação da Educação Inclusiva pode produzir mudanças positivas nas atitudes sociais dos professores (Ahmmed et al., 2014).

É evidente a importância de investigações científicas sobre as intervenções relacionadas à inclusão escolar. Estudos devem ser ampliados no sentido de transporem o simples levantamento de dados sobre as atitudes sociais para investigaçóes de possíveis intervençóes que promovam de modo planejado as mudanças das atitudes sociais em relação à inclusão. Salientase a importância do rigor científico necessário a tais investigaçóes, algo um tanto negligenciado em estudos de campo sobre atitudes sociais, quando não são utilizados instrumentos validados 
e padronizados ou delineamentos metodológicos adequados, o que pode levar a conclusóes superficiais e vagas, pautadas em meras inferências dos pesquisadores (Vieira \& Omote, 2017).

\section{Conclusóes}

As ações voltadas à formação de professores devem considerar aspectos relacionados às variáveis pessoais dos docentes, pois elas refletem sua visão de mundo e de educação e influenciam suas interaçóes com os alunos e as condutas em sala de aula. O professor é o grande modelo para seus alunos; suas ações e seu discurso são observados atentamente pelos estudantes, que intencional ou inconscientemente os reproduzem em seus comportamentos e interaçóes. Assim, o professor necessita conscientizar-se a respeito de seus próprios sentimentos, concepçóes e ações em relação às pessoas PAEE. Precisa aprender a desenvolvê-los adequadamente e esforçar-se para expressá-los de modo a colaborar para a construção de conhecimentos adequados e de atitudes sociais favoráveis à inclusão de seu alunado. A implementação da Educação Inclusiva depende não apenas da competência didático-pedagógica dos professores, mas das atitudes sociais favoráveis à inclusão por parte de toda a comunidade escolar.

O docente é o principal responsável pela mediação e pelo manejo das relaçôes interpessoais na sala de aula. O planejamento e a execução das atividades diárias no cotidiano escolar podem tornar-se oportunidades de vivências mais ou menos inclusivas, que englobam desde adequaçóes individualizadas de materiais e estratégias pedagógicas que atendam às necessidades de cada aluno, para que todos possam aprender, participar das atividades a seu modo e demonstrar suas habilidades, até a mediação direta das interaçóes entre os estudantes.

Essas relaçôes interpessoais podem ser afetadas por decisôes docentes que incluem a disposição das mesas e cadeiras na sala, a formação dos grupos para as tarefas, o incentivo à cooperação entre pares, o rodízio de papéis de liderança e colaboração, a construção de um sentimento de pertencimento grupal, a empatia, a valorização das decisóes coletivas, a mediação de conflitos, a expressão salutar de afetos positivos e negativos, e o respeito às singularidades, dentre tantas outras possibilidades.

Tais elementos precisam ser trabalhados na formação docente e na prática diária. Deve ser ressaltada também a participação ativa dos estudantes como sujeitos nos processos de ensino e de aprendizagem e na construção de uma cultura inclusiva. Os alunos devem ser ouvidos atentamente, chamados a opinar, estimulados à criação de propostas de melhoria do ambiente em sala de aula e à aplicação destas na prática do cotidiano escolar. Além da intensa influência que podem exercer na formação e na mudança das atitudes sociais de seus estudantes, os professores também têm muito a aprender com os estudantes, espontâneos em suas açóes e receptivos à reflexão e às transformações. A relaçáo professor-aluno representa o ponto central dos processos de ensino, de aprendizagem e de inclusão, merecendo maior atenção em intervençóes e pesquisas científicas.

Além dos processos de educação continuada, mais pontuais e temáticos, é preciso criar espaços de educação permanente, momentos de reflexão sobre vivências e angústias, estudo conjunto, troca de experiências e contato com profissionais de diferentes áreas do conhecimento, entre tantas alternativas que podem contribuir para maior segurança e satisfação dos professores em relação ao trabalho docente. Isso certamente pode refletir nas relaçóes pro- 
dutivas com todos os alunos, com e sem deficiência, e em uma prática pedagógica efetiva e inclusiva, gratificante e edificante para todas as partes envolvidas na educação escolar inclusiva.

Por fim, ainda que possa aparentemente estar na contramão das mensagens otimistas a respeito do ensino inclusivo de todos os estudantes, é preciso lembrar que nem todas as crianças e nem todos os jovens com necessidades especiais podem ser atendidos em classes de ensino comum. Estas têm objetivos precípuos que não podem ser negligenciados na tentativa de atender a necessidades especiais não educacionais que indivíduos com algumas patologias incapacitantes apresentam. E, também na decisão sobre a colocação ou não dessas crianças em classes de ensino comum, devem prevalecer as atitudes sociais favoráveis à inclusão. $\mathrm{O}$ encaminhamento a serviços especiais, nos quais necessidades diferenciadas podem ser atendidas, precisa ser um ato de acolhimento e inclusão, e não de discriminação e rejeição.

\section{REFERÊNCIAS}

Ahmmed, M., Sharma, U., \& Deppeler, J. (2014). Variables affecting teachers' intentions to include students with disabilities in regular primary schools in Bangladesh. Disability \& Society, 29, $317-$ 331. https://doi.org/10.1080/09687599.2013.796878

Allport, G. W. (1954). The Nature of prejudice. Addison Wesley.

Avramidis, E., \& Kalyva, E. (2007). The influence of teaching experience and professional development on Greek teachers' attitudes towards inclusion. European Journal of Special Needs Education, 22(4), 367-389. https://doi.org/10.1080/08856250701649989

Balboni, G., \& Pedrabissi, L. (2000). Attitudes of Italian teachers and parents toward school inclusion of students with mental retardation: the role of experience. Education and Training in Mental Retardation and Developmental Disabilities, 35(2), 148-159.

Berry, R. A. W. (2010). Preservice and early career teachers' attitudes toward inclusion, instructional accommodations, and fairness: three profiles. The Teacher Educator, 45(2), 75-95. https://doi.org/ $10.1080 / 08878731003623677$

Brito, M. C. (2017). Transtornos do espectro do autismo e educação inclusiva: análise de atitudes sociais de professores e alunos frente à inclusão. Revista Educação Especial, 30(59), 657-667. https://doi. org/10.5902/1984686X28086

Brunhara, J. A., Berberian, A. P., Guarinello, A. C., Biscouto, A. R., Krüger, S., Silva, D. V. da., \& Ferla, J. B. da S. (2019). Acessibilidade da pessoa com deficiência no ensino superior: atitudes sociais de alunos e professores de uma instituição de ensino superior. Revista CEFAC, 21(3), e13018. http:// dx.doi.org/10.1590/1982-0216/201921313018

Capellini, V. L. M. F., Rodrigues, O. M. P. R., \& Reis, V. L. dos. (2013). Atitudes sociais de profissionais da educação em relação à inclusão e suas variáveis demográficas [Apresentação de artigo]. 43a Reunião Anual da Sociedade Brasileira de Psicologia, Aracaju, Sergipe.

Chopra, R. (2008). Factors influencing Elementary School teachers' attitudes towards inclusive education. British Educational Research Association Annual Conference. Edinburgh, Escócia.

Cook, B. G. (2002). Inclusive attitudes, strengths, and weaknesses of pre-service general educators enrolled in a curriculum infusion teacher preparation program. Teacher Education and Special Education, 25(3), 262-277. https://doi.org/10.1177/088840640202500306 
Crochík, J. L. (2001). Teoria crítica da sociedade e estudos sobre o preconceito. Revista Psicologia Política, 1(1), 67-99.

Del Prette, Z. A. P., \& Del Prette, A. (2001). Inventário de habilidades sociais (HID Del Prette): manual de aplicação, apuração e interpretação. Casa do Psicólogo.

Delgado-Pinheiro, E. M. C. (2003). Professores do Ensino Regular e a Educação Inclusiva de alunos com perda auditiva [Tese de Doutorado, Universidade Estadual Paulista, Faculdade de Filosofia e Ciências]. Repositório da Universidade Estadual Paulista. https://www.teses.usp.br/teses/ disponiveis/59/59137/tde-24102013-153936/publico/Maria_do_P_Socorro_D_Marques_ doutorado.pdf

Festinger, L. (1957). A theory of cognitive dissonance. Row Peterson.

Forlin, C., Loreman, T., Sharma, U., \& Earle, C. (2009). Demographic differences in changing preservice teachers attitudes, sentiments, and concerns about inclusive education. International Journal of Inclusive Education, 13(2), 195-209. https://doi.org/10.1080/13603110701365356

Gal, E., Schreur, N., \& Engel-Yeger, B. (2010). Inclusion of children with disabilities: teachers' attitudes and requirements for environmental accommodations. International Journal of Special Education, 25(2), 89-99.

Gash, H. (1993). A constructivist attempt to change attitudes towards children with special needs. European Journal of Special Needs Education, 8, 106-125. https://doi.org/10.1080/0885625930080203

Gatti, B. A. (2003). Formação continuada de professores: a questão psicossocial. Cadernos de Pesquisa, 119, 191-204. https://doi.org/10.1590/S0100-15742003000200010

Golmic, B. A., \& Hansen, M. A. (2012). Attitude, sentiments and concerns of pre-service teachers after their included experience. International Journal of Special Education, 27(1), 27-36.

Gouveia, C. S. P. (2019). Atitudes e práticas dos professores do $2 .^{\circ}$ e $3 .^{\circ}$ ciclos face à inclusão de alunos com Necessidades Educativas na sala de aula, da rede pública e privada da Região Autónoma da Madeira [Dissertaçáo de Mestrado, Universidade Fernando Pessoa, Faculdade de Ciências Humanas e Sociais]. Repositório da Universidade Fernando Pessoa. https://bdigital.ufp.pt/handle/10284/8672

Kijima, G. Y. M. (2008). Análise de atitudes sociais de profissionais da educação frente à inclusão [Monografia de Especialização, Universidade Estadual Paulista]. São Paulo, Brasil.

Kim, J., Park, E., \& Snell, M. E. (2005). Impact of information and weekly contact on attitudes of Korean general educators and nondisabled students regarding peers with disabilities. Mental Retardation, 43(6), 401-415. https://doi.org/10.1352/0047-6765(2005)43[401:IOIAWC]2.0.CO;2

Kuittinen, E. (2017). Inclusive education from teachers'perspective: Exploring Chilean teachers' attitudes and self-efficacy. University of Jyväskylä.

Kuyini, A. B., Desai, I., \& Sharma, U. (2018) Teachers' self-efficacy beliefs, attitudes and concerns about implementing inclusive education in Ghana. International Journal of Inclusive Education, 24(14), 1509-1526. https://doi.org/10.1080/13603116.2018.1544298

Leung, C., \& Mak, K. (2010). Training, understanding, and the attitudes of primary school teachers regarding inclusive education in Hong Kong. International Journal of Inclusive Education, 14(8), 829-842. https://doi.org/10.1080/13603110902748947 
Male, D. B. (2011). The Impact of a professional development program e on teachers attitudes towards inclusion. Support for Learning, 26(4), 182-186. https://doi.org/10.1111/j.14679604.2011.01500.x

Martins, L. de A. R. (2006). Formação de professores numa perspectiva inclusiva: algumas constataçóes. In E. J. Manzini (Org), Inclusão e acessibilidade (pp. 17-27). ABPEE.

Menino-Mencia, G. F. (2020). Influência de um programa de formação continuada sobre crenças e atitudes dos professores em relaçâo a Educação Inclusiva [Tese de Doutorado, Universidade Estadual Paulista, Faculdade de Ciências]. Repositório da Universidade Estadual Paulista. https://repositorio.unesp. br/handle/11449/192128

Mintz, J. (2007). Attitudes of primary initial teacher training students to special educational needs and inclusion. Support for Learning, 22(1), 03-08. https://doi.org/10.1111/j.1467-9604.2007.00438.x

Omote, S., \& Vieira, C. M. (2018). A importância das variáveis pessoais do professor na sua formação para a educação inclusiva. In A. A. S. de Oliveira. (Org.), Educaçâo especial e inclusiva: contornos contemporâneos em educação e saúde (pp. 11-11). CRV.

Omote, S., Oliveira, A. A. S. de, Baleotti, L. R., \& Martins, S. E. S. de O. (2005). Mudança de atitudes sociais em relação à inclusão. Paidéia, 15(32), 387-398. https://doi.org/10.1590/S0103863X2005000300008

Organização das Nações Unidas para a Educação, a Ciência e a Cultura. (1994). Declaração de Salamanca: Sobre Princípios, Políticas e Práticas na Área das Necessidades Educativas Especiais. Salamanca. http:// portal.mec.gov.br/seesp/arquivos/pdf/salamanca.pdf

Parasuram, K. (2006). Variables that affect teachers' attitudes towards disability and inclusive education in Mumbai, India. Disability \& Society, 21(3),231-242. https://doi.org/10.1080/09687590600617352

Pereira Júnior, A. A. (2009). Atitudes sociais de professores da rede de ensino regular municipal de Guarapuava/PT em relação à Educação Inclusiva [Dissertação de Mestrado, Universidade Estadual Paulista, Faculdade de Filosofia e Ciências]. Repositório da Universidade Estadual Paulista. https:// repositorio.unesp.br/handle/11449/91206

Pletsch, M. D. (2009). A Formação de professores para a educação inclusiva: legislação, diretrizes políticas e resultados de pesquisas. Educar, 33, 143-156. https://doi.org/10.1590/S010440602009000100010

Rodrigues, A., Assmar, E. M. L., \& Jablonsky, B. (2007). Psicologia social. Vozes.

Saloviita, T. (2020). Teacher attitudes towards the inclusion of students with support needs. Journal of Research in Special Educational Needs, 20(1), 64-73. https://doi.org/10.1111/1471-3802.12466

Santos, B. S. dos, Antunes, D. D., \& Bernardi, J. (2008). O docente e sua subjetividade nos processos motivacionais. Educação, 31(1), 46-53.

Sekkel, M. C., Zanelatto, R., \& Brandão, S. de B. (2010). Ambientes inclusivos na educação infantil: possibilidades e impedimentos. Psicologia em Estudo, 15(1), 117-126. http://dx.doi.org/10.1590/ S1413-73722010000100013

Sharma, U. (2012). Changing pre-service teachers' beliefs to teach in inclusive classrooms in Victoria, Australia. Australian Journal of Teacher Education, 37(10), 52-66. http://dx.doi.org/10.14221/ ajte. $2012 \mathrm{v} 37 \mathrm{n} 10.6$ 
Silva, E. (2009). Formação de professores em educação especial: a experiência da UNESP - Campus de Marília [Dissertação de Mestrado, Universidade Estadual Paulista, Faculdade de Filosofia e Ciências]. Repositório da Universidade Estadual Paulista. https://repositorio.unesp.br/handle/11449/91209

Silva, E. G. (2008). O perfil docente para a educação inclusiva: uma análise a partir da legislação e das atitudes e habilidades sociais [Tese de Doutorado, Universidade Estadual Paulista, Faculdade de Filosofia e Ciências]. Repositório da Universidade Estadual Paulista. https://repositorio.unesp.br/ handle/11449/102241

Souza, M. M. G. da S. e. (2011). Atitudes sociais em relação à inclusão e concepçôes sobre atendimento educacional especializado: o ponto de vista de alunos de um curso de especialização [Monografia de Especialização, Universidade Estadual Paulista, Faculdade de Filosofia e Ciências]. São Paulo, Brasil.

Souza, M. M. G. da S. e. (2017). Atitudes sociais em relação à inclusão e concepção sobre atendimento educacional especializado na formação de especialistas em Educação Especial. Revista Educação Especial, 30(59), 751-762. http://dx.doi.org/10.5902/1984686X28431

Verde, E. J. S. R. C., Corrêa, L. da S., \& Santos, J. O. L. dos. (2020). Atitudes dos professores de Educação Física em relação à inclusão de alunos com deficiência: uma revisão sistemática da literatura. Educamazônia - Educação, Sociedade e Meio Ambiente, 24(1), 149-178.

Vieira, C. M. (2014). Atitudes sociais em relação à inclusão: efeitos da capacitação de professores para ministrar programa informativo aos alunos [Tese de Doutorado, Universidade Estadual Paulista, Faculdade de Filosofia e Ciências]. Repositório da Universidade Estadual Paulista. https://repositorio.unesp.br/ handle/11449/114037

Vieira, C. M., \& Omote, S. (2017). Aspectos metodológicos e éticos de uma pesquisa sobre mudanças de atitudes sociais de professores e estudantes em relação à inclusão. Reflexão e Ação, 25(3), 299320. https://doi.org/10.17058/rea.v25i3.9727

Wilkins, T., \& Nietfeld, J. L. (2004). The effect of a school-wide inclusion training program upon teachers' attitudes about inclusion. Journal of Research in Special Educational Needs, 4(3), 115-121. https://doi.org/10.1111/j.1471-3802.2004.00026.x

Woodcock, S., Hemmings, B., \& Kay, R. (2012). Does study of an inclusive education subject influence pre-service teachers' concerns and self-efficacy about inclusion?. Australian Journal of Teacher Education, 37(6). http://dx.doi.org/10.14221/ajte.2012v37n6.5

Yada, A., \& Savolainen, H. (2017). 'Japanese in-service teachers' attitudes toward inclusive education and self-efficacy for inclusive practices. Teaching and Teacher Education, 64, 222-229. https://doi. org/10.1016/j.tate.2017.02.005

Recebido em: 15/12/2020

Reformulado em: 15/03/2021

Aprovado em: 20/04/2021 